\title{
ASTROCYTE-LIKE GLIA IN THE PERIPHERAL NERVOUS SYSTEM: AN IMMUNOHISTOCHEMICAL STUDY OF ENTERIC GLIA $^{1}$
}

\author{
KRISTJÅN R. JESSEN ${ }^{*}, 2$ AND RHONA MIRSKY \\ ${ }^{*}$ MRC Neuroimmunology Group, Department of Zoology, and $\ddagger$ Department of Anatomy and Embryology, University College, \\ Gower Street, London WC1E 6BT, England
}

Received January 5, 1983; Revised May 4, 1983; Accepted May 5, 1983

\begin{abstract}
The similarities between the enteric nervous system of the gut and the central nervous system (CNS), both of which function as complex integrative nervous networks, include striking ultrastructural similarities between the glia of the enteric nervous sytem and the astrocytic glia of the CNS. In this paper we have determined whether this anatomical resemblance also extends to the molecular level by examining the enteric glial cells to see whether they express several surface and intracellular molecules which are highly restricted to glia and to astrocytes in particular. Indirect immunofluoresence was used to visualize the antigens in frozen sections of gut wall and in whole mount, tissue culture, and freshly dissected preparations of myenteric and submucous plexuses from rats of various ages. It was found that enteric glial cells expressed the intracellular proteins glial fibrillary acidic protein, glutamine synthetase, and vimentin both in situ and in culture. The surface antigen Ran2 was expressed in situ but not in culture, and the surface antigen Ran-1 was expressed in culture but not in situ. Cultured enteric glial cells did not express fibronectin in significant quantity, nor did they make galactocerebroside. From these results we conclude that the adult phenotype of enteric glia in situ closely resembles that of astrocytes, while in culture some of their cell surface features change, reverting to those seen during development. Because these cells possess distinctive molecular features and numerically form one of the major populations of peripheral glia, it is appropriate to classify them as a third distinctive category of peripheral glial cells, in addition to satellite and Schwann cells. The molecular similarities between these cells and astrocytes, in addition to their anatomical resemblance, suggest that a further study of enteric glia will provide new insights into the role of glia in integrative nervous tissues.
\end{abstract}

The enteric nervous system (ENS) of the gastrointestinal tract and the central nervous system (CNS) are both complex and integrative nervous networks which show striking histological, biochemical, and functional similarities (Furness and Costa, 1980; Gershon, 1981; Wood, 1981; Jessen and Burnstock, 1982). It is interesting, therefore, that the astrocytic glia of the CNS and the glial cells of the ENS closely resemble each other in gross morphology, ultrastructure, and relationships with neuronal cell bodies and processes (Gabella, 1971, 1981).

\footnotetext{
${ }^{1}$ This work was supported by the Mental Health Foundation and the Medical Research Council of Great Britain. We would like to thank Drs. A. Bignami, E. Bock, R. Pruss, P. Woodhams, E. Frank, F. Ramaekers, O. S. Jorgensen, K. L. Fields, B. Ranscht, E. Ruoslahti, and R. Morris for gifts of antiserum, Drs. G. Gabella, M. Raff, and A. E. Warner for helpful discussion, and Mrs. Shihan Jayasuriya for typing the manuscript.

${ }^{2}$ To whom correspondence should be addressed.
}

This raises the possibility that enteric glia and astrocytes share similar functions in the two systems and that the ENS, which is simpler in organization and more accessible, could serve as a model for understanding some of the basic principles of glial function and neuroglia interactions in integrative nervous networks.

In this context it is important to establish whether the similarities between enteric glial cells and astrocytes are limited to a morphological resemblance or whether they also extend to the molecular level. We have therefore examined these cells for the presence of several intracellular and surface molecules associated with neuroglia and, in particular, with astrocytes.

These molecules include the intermediate filament components glial fibrillary acidic protein (GFAP) (Ludwin et al., 1976; Schachner et al., 1977) and vimentin (Lazarides, 1980), the intracellular enzyme glutamine synthetase (Martinez-Hernandez et al., 1977), and the 
cell surface components Ran-1 (Fields et al., 1975; Brockes et al., 1977), Ran-2 (Bartlett et al., 1981), fibronectin (Wartiovaara et al., 1974), and galactocerebroside (Raff et al., 1978). Using immunofluorescence, we investigated the distribution of these molecules in tissue sections, whole mount preparations, enteric plexuses isolated from the gut wall, and tissue culture preparations. Part of this work has already appeared in preliminary form (Jessen and Mirsky, 1980).

\section{Materials and Methods}

\section{Tissue preparations}

Frozen sections. Segments of small intestine and colon were removed from $\mathrm{W} / \mathrm{Fu}$ rats of various ages, placed in a drop of OCT compound (Lab-Tek Products Inc.) on a piece of cork, and immersed in isopentane which had been cooled in liquid $\mathrm{N}_{2}$. Five- and $10-\mu \mathrm{m}$ frozen sections were cut at $-15^{\circ} \mathrm{C}$ on a Bright cryostat and thawed onto dry microscope slides. In some experiments the sections were treated with Triton X-100 (0.5\%) for $15 \mathrm{~min}$ before the application of antibodies.

Freshly dissected plexus. Colon from 7- to 21-day-old rats was washed thoroughly in minimal Eagle's medium with 0.015 м HEPES buffer (MEM-HEPES) before incubation in a mixture of collagenase $(1 \mathrm{mg} / \mathrm{ml}$ ) (type SC-III, Worthington Biochemcial Corp.), hyaluronidase $(1.2 \mathrm{mg} / \mathrm{ml})$ (type I-S, Sigma Chemical Co.), and chicken egg white trypsin inhibitor $(0.3 \mathrm{mg} / \mathrm{ml})$ (type II-0, Sigma) in Dulbecco's modified MEM for $3 \mathrm{hr}$ at $37^{\circ} \mathrm{C}$ in $95 \%$ air $/ 5 \% \mathrm{CO}_{2}$. The tissue was then transferred to MEMHEPES and the myenteric plexus was dissected completely free of both the longitudinal and circular muscle layers as described elsewhere (Jessen et al., 1983a). In some experiments dorsal root ganglia (DRG) were treated with enzymes in identical fashion and were gently teased apart before immunostaining.

Tissue culture. Explant cultures of the myenteric plexus from the colon of 7- to 21-day-old rats were set up as described previously (Jessen et al., 1983a).

Whole mount preparations. The outer part of the gut wall, containing the myenteric plexus sandwiched in a thin layer between the longitudinal and the circular muscle coats, was removed by easing it off a segment of intestine previously mounted on a Pasteur pipette and was placed, with the longitudinal muscle downward, on a microscope slide. While keeping the tissue moist, the circular muscle was partially or totally removed using fine forceps and swab-sticks, thus exposing the plexus. The preparation was then fixed. In some experiments pieces of gut were fixed in $15 \%$ picric acid/ $2 \%$ formaldehyde in phosphate-buffered saline (PBS) (Stefani et al., 1967; Costa et al., 1980), and the myenteric or submucous plexus was exposed by dissecting off the appropriate tissues.

\section{Antisera}

For routine studies, a rabbit antiserum to human GFAP, supplied by Dr. R. Pruss, was employed. The specificity of this serum has been described previously (Jessen and Mirsky, 1980). It was used at dilutions of
$1: 1,000$ or $1: 10,000$ in incubations for $30 \mathrm{~min}$ to $1 \mathrm{hr}$ at room temperature or $18 \mathrm{hr}$ at $4^{\circ} \mathrm{C}$, respectively. All results obtained with this antiserum were confirmed using four additional rabbit antisera raised against GFAP (supplied by Drs. A. Bignami, E. Bock, R. Pruss, and P. Woodhams). Rabbit antiserum to vimentin from BHK cells was supplied by Dr. E. Frank. On immunoblotting, this serum reacts with vimentin and vimentin breakdown products only (Frank and Warren, 1981). It was used at a dilution of 1:500 in overnight incubations for $18 \mathrm{hr}$ at $4^{\circ} \mathrm{C}$. In experiments on whole mounts, rabbit antiserum raised against bovine lens vimentin and supplied by Dr. F. Ramaekers was used (Ramaekers et al., 1982). In rat this antiserum reacts exclusively with vimentin in immunoblotting experiments (Dr. D. Lawson, personal communication). Rabbit antiserum to sheep glutamine synthetase was supplied by Dr. O. S. Jorgensen and was tested for specificity by Dr. A. Norenberg. It was used at a dilution of 1:25 in 1-hr incubations at room temperature. Mouse anti-Ran-1, supplied by Dr. K. L. Fields, was used at 1:50 or 1:100 in 30-min incubations at room temperature. It has been fully characterized elsewhere (Fields et al., 1975; Brockes et al., 1977, 1979). Monoclonal mouse anti-Ran-2 was produced and characterized by Bartlett et al. (1981). Monoclonal mouse anti-galactocerebroside was supplied and characterized by Dr. B. Ranscht (Ranscht et al., 1982). Ascites fluid produced by these hybridomas was diluted 1:100 for 30-min incubations at room temperature. Rabbit anti-fibronectin serum was supplied and characterized by Dr. E. Ruoslahti and was used at a dilution of 1:100 (Wartiovaara et al., 1974). Tetramethyl rhodamine conjugated to goat antimouse Ig (G anti-MIg-Rd) (Cappel Laboratories Ltd.) adsorbed with rabbit Ig to remove cross-reacting antibodies, tetramethyl rhodamine-conjugated goat anti-rabbit Ig (G anti-RIg-Rd) (Nordic Laboratories Ltd.) adsorbed with mouse Ig to remove cross-reacting antibodies, and fluorescein-conjugated sheep anti-rabbit $\mathrm{F}\left(\mathrm{ab}^{\prime}\right)_{2}$ (Sh anti-RIg $\left(\mathrm{F}\left(\mathrm{ab}^{\prime}\right)_{2}\right)$ - $\mathrm{Fl}$ ) adsorbed with rat Ig, supplied by $\mathrm{Dr}$. R. Morris, were used at a dilution of 1:100. All antibody solutions were diluted in MEM-HEPES containing $10 \%$ fetal calf serum and $0.1 \mathrm{M}$ lysine.

\section{Indirect immunofluorescence}

Frozen sections. Five- or $10-\mu \mathrm{m}$ cryostat sections were incubated for $18 \mathrm{hr}$ at $4^{\circ} \mathrm{C}$ (GFAP and vimentin antisera) or $1 \mathrm{hr}$ at room temperature (GFAP and glutamine synthetase antisera). After the 18-hr incubation, sections were allowed to stand for $1 \mathrm{hr}$ at room temperature and then were given three 5-min washes in MEM-HEPES. The sections were then incubated with $\mathrm{G}$ anti-RIg-Rd or $\mathrm{Sh}$ anti-RIg $\left(\mathrm{F}\left(\mathrm{ab}^{\prime}\right)_{2}-\mathrm{Fl}\right.$ for $30 \mathrm{~min}$ at room temperature and again were washed three times in MEM-HEPES, before being fixed in $95 \%$ ethanol $/ 5 \%$ acetic acid for 10 min at $-20^{\circ} \mathrm{C}$, washed very thoroughly, and mounted in $50 \%$ glycerol $/ 50 \%$ PBS and sealed.

Whole mount preparations. Whole mount preparations fixed with picric acid/formaldehyde were incubated with antibody to GFAP for $30 \mathrm{~min}$ at room temperature, followed by three 5-min washes in MEM-HEPES. The preparations were then treated with Sh anti-RIg 

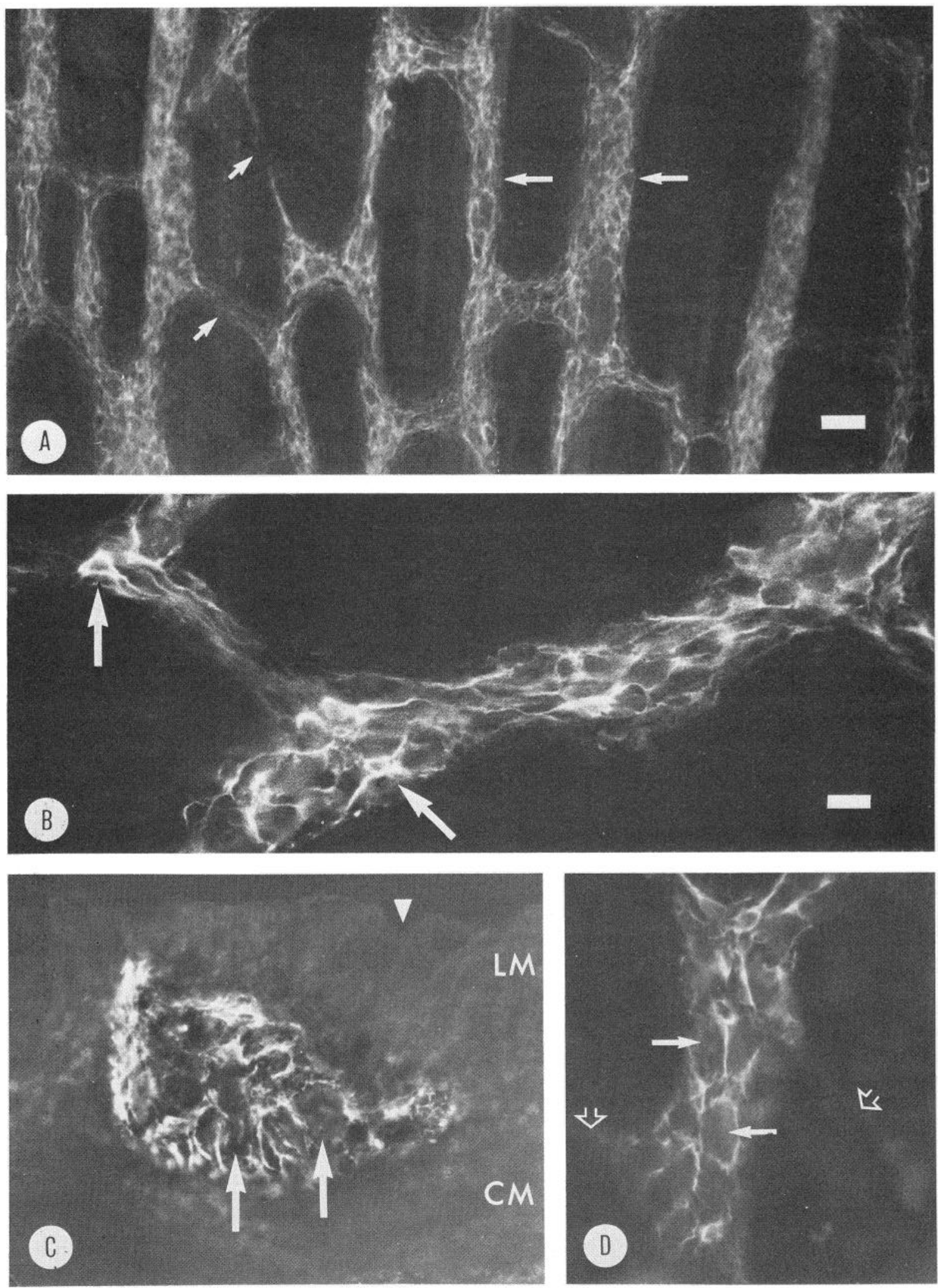

Figure 1. A, Low power view of GFAP-like immunoreactivity in the myenteric plexus in a whole mount preparation of ileum fixed in picric acid/formaldehyde. The glial cells within the ganglia (examples of ganglia labeled with long arrows) show intense immunoreaction which is weaker or absent in most of the glial cells in the interconnecting nerve strands between the ganglia (examples labeled with short arrows). Note that both neuronal cell bodies within the plexus and smooth muscle cells beneath the plexus are unstained. Bar, $50 \mu \mathrm{m}$. B, Higher magnification view of GFAP-like immunoreactivity in two interconnected ganglia of the myenteric plexus in a preparation similar to $A$. Note the intense reaction in the cell bodies (example labeled with arrows) 
$\left(\mathrm{F}\left(\mathrm{ab}^{\prime}\right)_{2}\right)-\mathrm{Fl}$ for $40 \mathrm{~min}$, washed three times, and mounted in $50 \%$ glycerol $/ 50 \%$ PBS.

Whole mount preparations of rat myenteric plexus were treated with $95 \%$ ethanol $/ 5 \%$ acetic acid for $10 \mathrm{~min}$ at $-20^{\circ} \mathrm{C}$ to permeabilize the cells and were incubated with antibody to vimentin for $30 \mathrm{~min}$ at room temperature, followed by three 5-min washes in MEM-HEPES. The preparations were then treated with Sh anti-RIg $\left(\mathrm{F}\left(\mathrm{ab}^{\prime}\right)_{2}\right)-\mathrm{Fl}$ for $30 \mathrm{~min}$, washed three times, and mounted in $50 \%$ glycerol $/ 50 \%$ PBS.

Freshly dissected plexus. Small pieces of freshly dissected plexus were placed on a microscope slide, gently stretched out under the dissecting microscope, and kept moist. They were then incubated with antibody to Ran1 or Ran-2 for $30 \mathrm{~min}$ at room temperature. After three 5-min washes in MEM-HEPES, G anti-MIg-Rd was applied for $30 \mathrm{~min}$. After three additional washes the preparation was treated with $95 \%$ ethanol $/ 5 \%$ acetic acid for $10 \mathrm{~min}$ at $-20^{\circ} \mathrm{C}$, washed very thoroughly, and mounted in $50 \%$ glycerol $/ 50 \%$ PBS.

Cultures. For surface immunofluorescence, cultures of myenteric plexus from 7- to 21-day-old rat proximal colon were treated in the same way as freshly dissected plexuses and incubated with antibodies to Ran-1, Ran2 , galactocerebroside, and fibronectin.

For intracellular immunofluorescence cultures were treated with $95 \%$ ethanol $/ 5 \%$ acetic acid for $10 \mathrm{~min}$ at $-20^{\circ} \mathrm{C}$ and washed thoroughly with MEM-HEPES before application of antibodies to GFAP, vimentin, and glutamine synthetase for $30 \mathrm{~min}$ at room temperature. Subsequent treatment was as described for whole mount preparations.

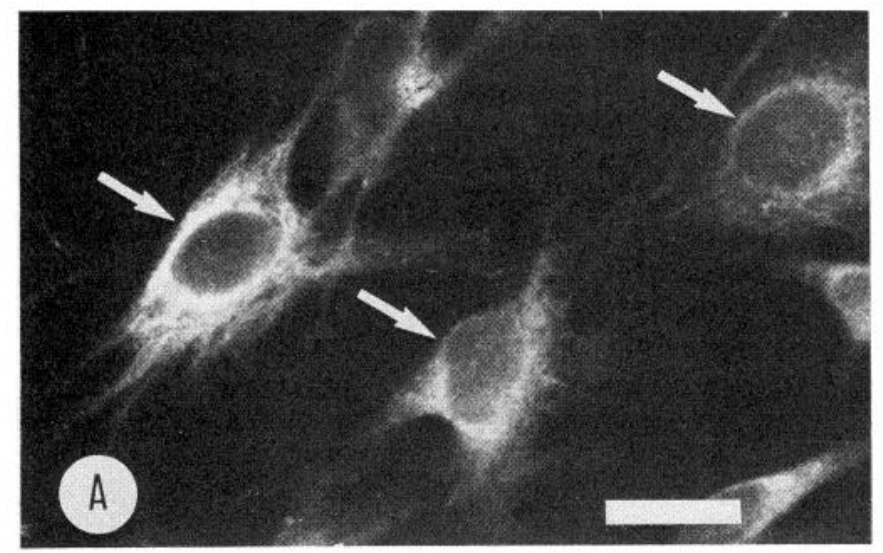

For double label immunofluorescence, cultures were labeled sequentially following first the procedure for surface labeling, then permeabilizing with $95 \%$ ethanol/ $5 \%$ acetic acid, followed by the procedure for intracellular labeling.

\section{Results}

Although it is clear that none of the five antisera to GFAP used in this study react significantly with any of the other types of 10-nm intermediate filaments using the conditions we have used for immunofluorescence (see below), the possibility that the antisera are detecting a glial filament protein closely related but not identical to GFAP cannot be ruled out. We therefore refer to GFAPlike immunoreactivity. Since the same arguments apply to the other antisera and monoclonal antibodies, we have used a similar nomenclature throughout.

\section{Intracellular molecules}

GFAP-like immunoreactivity. In frozen sections of the gut wall, all of our GFAP antisera stained intensely in a highly characteristic pattern in both myenteric and submucous ganglia (Fig. 1C). The immunofluorescence appeared predominantly filamentous and, inside the ganglia, restricted to the enteric glia, a conclusion confirmed by tissue culture studies (see below). Immunoreactivity was also found in some Schwann cells associated with nerves in the circular layer of the external muscle coat and submucosa. In the glial cells of the myenteric plexus ganglia the immunofluorescence was more intense than that seen in astrocytes in comparable sections taken from cerebellum, whereas in the glial cells of the submucous

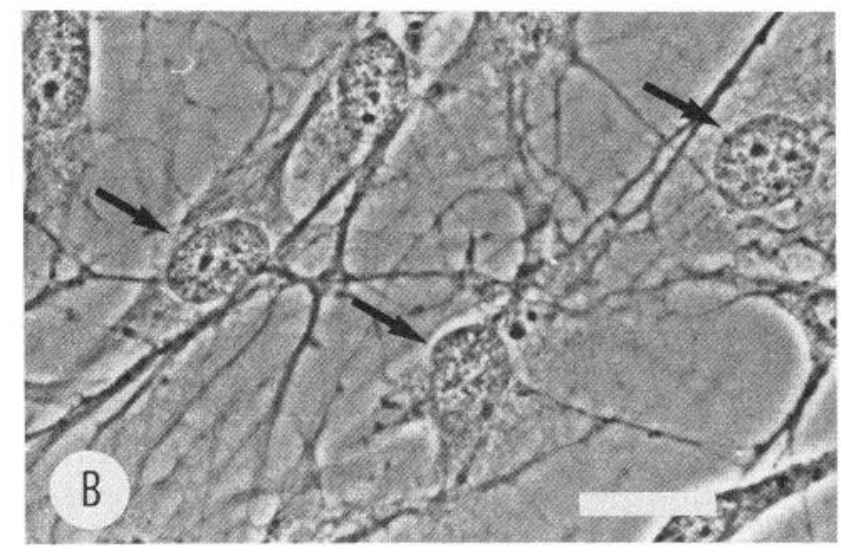

Figure 2. GFAP-like immunoreactivity in enteric glia in an explant culture of the myenteric plexus from a 7-day-old rat maintained in vitro for 10 days. The cells are viewed with $(A)$ fluorescein and $(B)$ phase contrast optics. Arrows point to corresponding areas in the two micrographs. Bar, $10 \mu \mathrm{m}$.

and fine processes of the enteric glia within the ganglia, and the weak reactivity in the connecting strand (cf. vimentin). The neurons lying between the glial processes and the muscle underneath the ganglia are not stained. $B a r, 10 \mu \mathrm{m}$. $C$, GFAP-like immunoreactivity in a $10-\mu \mathrm{m}$ frozen section of a myenteric plexus ganglion in the proximal colon. The staining pattern is similar to that seen in whole mount preparations with strong reactivity in the glial cells, branching among immunonegative neuronal elements (arrows). The muscle ( $L M$, longitudinal muscle; $C M$, circular muscle) and the connective tissue of the serosa lining the outside of the gut wall (arrowhead) and surrounding the ganglion are not stained (cf. vimentin). Magnification as in $B$. $D$, GFAPlike immunoreactivity in a ganglion of the submucous plexus in a whole mount preparation of proximal colon fixed with picric acid/formaldehyde. The staining pattern is similar to that seen in the myenteric plexus. Unstained neuronal cell bodies (example labeled with solid arrows) are seen among the glial cell processes, and there is an absence of immunoreactivity in the glia of the interconnecting strands (open arrows). Magnification as in $B$. 
plexus ganglia the intensity was similar to that seen in astrocytes. To see whether the glial cells in the interconnecting nerve strands between ganglia, within both the myenteric and submucous plexuses, also possessed GFAP-like proteins, whole mount preparations of the myenteric and submucous plexus were used, since they allow better visualization of the glia in these two locations (Fig. 1, $A, B$, and $D$ ). Such preparations have been employed extensively to investigate the distribution of neurotransmitters and neuropeptides in the enteric plexuses (Furness and Costa, 1980) but have not previously been used to examine immunoreactivity in glial cells. As shown in Figure $1, A, B$, and $D$, many glial cells in the interconnecting strands between the ganglia contained either little or no reactivity, whereas strong GFAP-like immunoreactivity was present in the glial cells within the ganglia. The nonglial cells in the gut wall, including muscle cells, epithelial cells, and connective tissue cells, were not stained by any of the GFAP antisera.

In newborn rats (postnatal day 0) GFAP-like immunoreactivity was clearly detectable in the ganglia of both the myenteric and submucous plexuses in the proximal colon, although adult levels of staining intensity were not attained until about postnatal day 14 .

To confirm that the GFAP-like immunoreactivity was confined to the enteric glia and to determine whether these cells, like astrocytes, maintain their phenotype when they are removed from contact with neuronal cell bodies and maintained in culture, we labeled explant cultures of the myenteric plexus from the rat colon (Fig. 2 ). These cultures are similar to the well characterized cultures of the myenteric plexus fromn the tenia coli of the guinea pig cecum (Baluk et al., 1983; Jessen et al., 1983a, b). They contain large numbers of enteric glia, which can be distinguished from fibroblasts not only on the basis of immunoreactivity (see below) but also because of their distinctive morphology and interaction with neurites. Figure 2 shows that glia, in cultures obtained from 7-day-old rats and maintained in vitro for 1 to 2 weeks, expressed GFAP-like immunoreactivity similar in intensity and intracellular distribution to that of astrocytes in comparable cultures obtained from 5-dayold rat cerebellum, although the filamentous pattern was not as clearly delineated as that of most astrocytes in culture.

Vimentin-like immunoreactivity. In frozen sections of gut wall, vimentin-like immunoreactivity was clearly present in myenteric and submucous ganglia in a pattern similar to that observed for GFAP (Fig. 3). Immunoreactivity was also seen in Schwann cells in the nerve bundles of the circular layer of the external muscle coat. Immunostaining of whole mount preparations of the myenteric plexus showed clearly that vimentin-immunoreactive filaments were not restricted to the enteric glia inside ganglia but were also found in glia accompanying the nerve fibers of the interconnecting strands (Fig. 4). Unlike GFAP, vimentin immunostaining was also found in the connective tissue of the gut wall, including the serosa, submucosa, and mucosa, in agreement with previous results (Frank and Warren, 1981) (Fig. 3).

Developmentally, vimentin immunoreactivity changed in the reverse manner to that of GFAP. At postnatal day 0 , very intense reaction was obtained in the glia of the myenteric ganglia, which fell gradually to adult levels by about postnatal day 20 .

To show unambiguously the glial localization of vi-

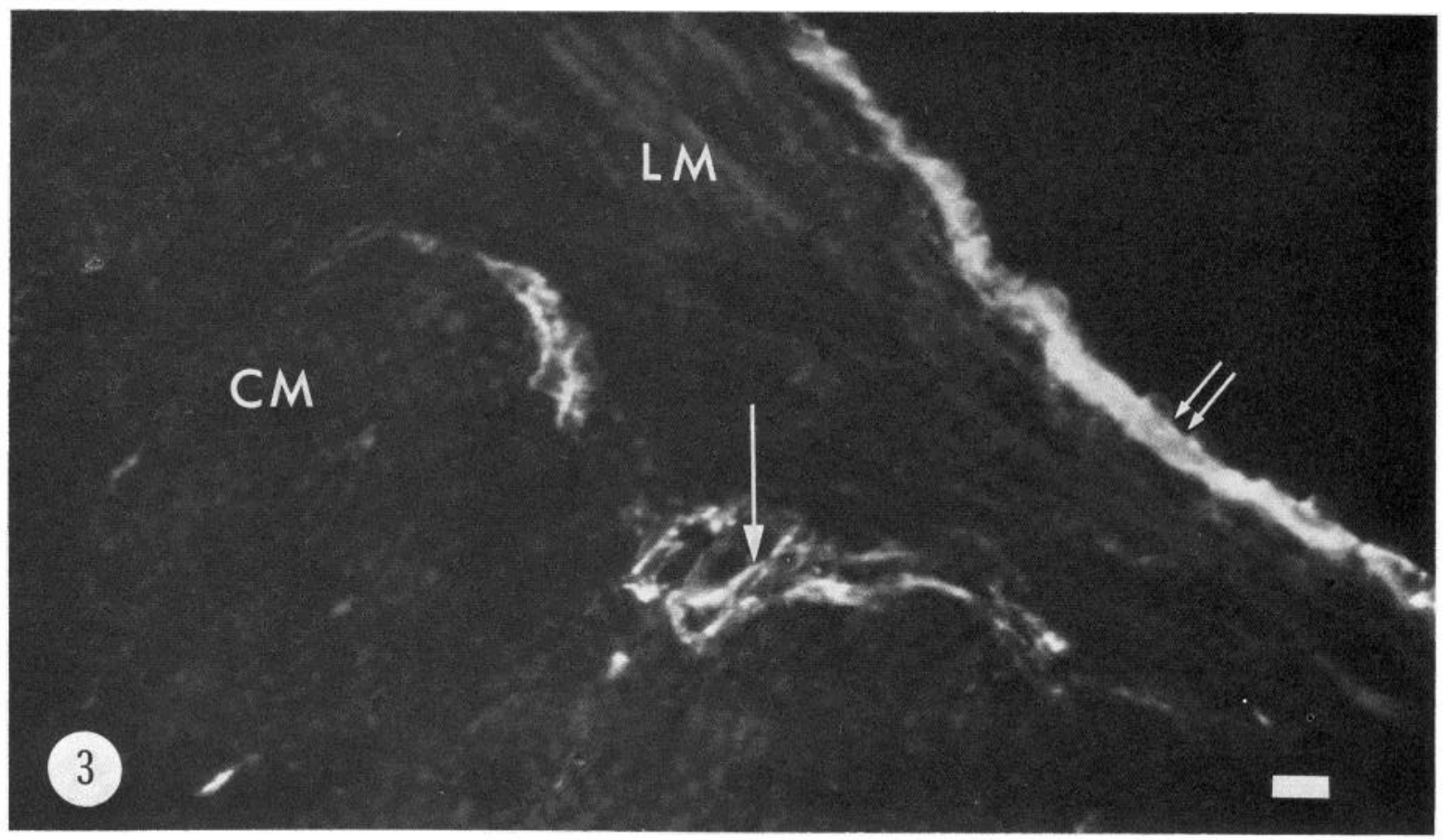

Figure 3. Vimentin-like immunoreactivity in a section of two small myenteric plexus ganglia in a $10-\mu \mathrm{m}$ frozen section of proximal colon treated with Triton X-100. Immunostaining is seen in glial cells inside the ganglia (example labeled with long arrow) and in the connective tissue of the serosa (short arrows). Unstained areas inside the ganglia correspond to the location of neuronal elements. The muscle ( $L M$, longitudinal muscle; $C M$, circular muscle) is unstained. Bar, $10 \mu \mathrm{m}$. 

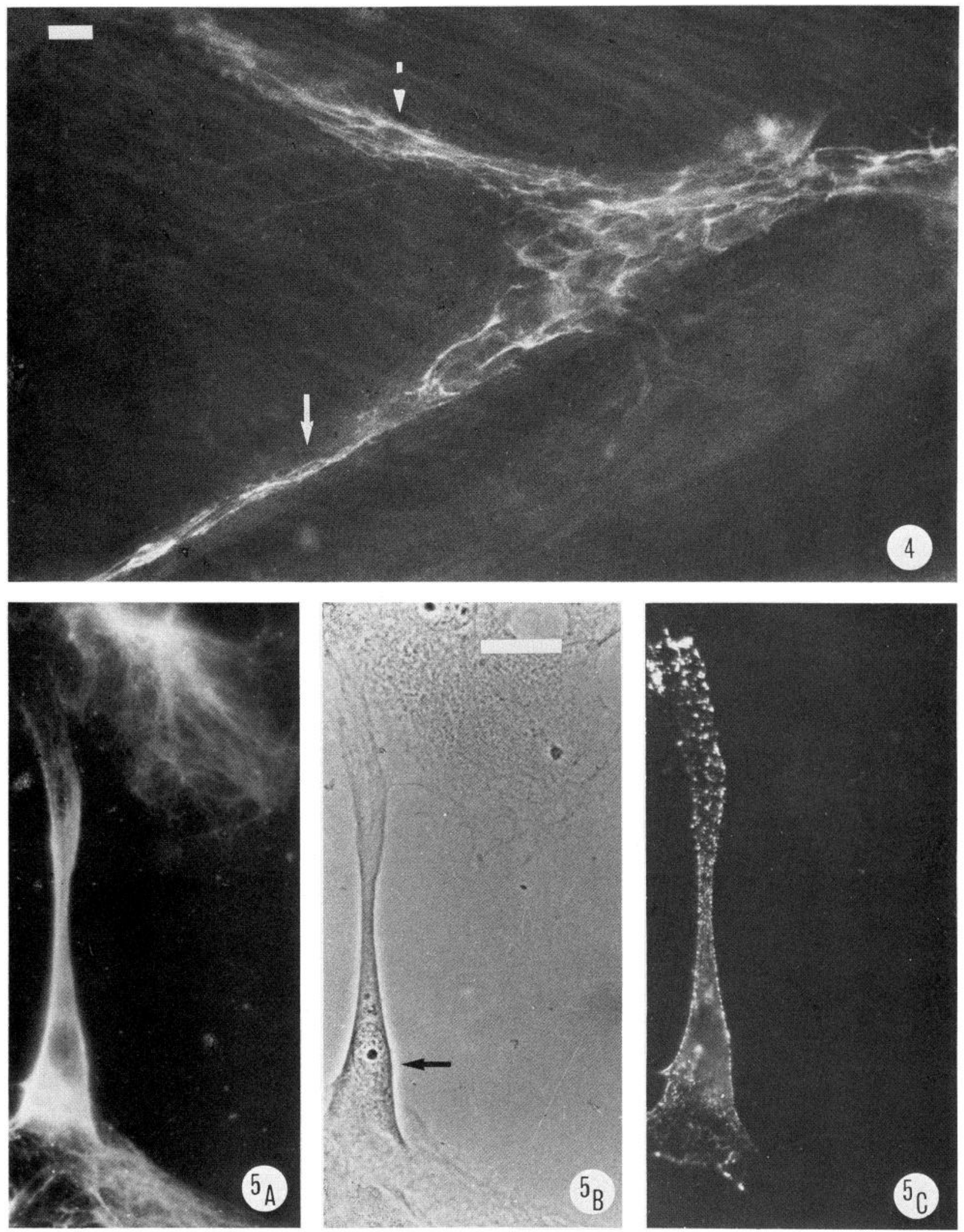

Figure 4. Vimentin-like immunoreactivity in the myenteric plexus in a whole mount preparation of the proximal colon fixed with acid/alcohol. Enteric glia within the single ganglion and in the two interconnecting strands (arrows) are equally strongly labeled (cf. GFAP). Neurons and smooth muscle cells are unlabeled. Bar, $10 \mu \mathrm{m}$.

Figure 5. Vimentin-like and Ran-1 immunoreactivity in an explant culture of the myenteric plexus from 7-day-old proximal colon maintained in vitro for 10 days. $B a r, 10 \mu \mathrm{m}$. A, Fluorescein optics to visualize vimentin; $B$, phase contrast optics; $C$, rhodamine optics to visualize Ran-1. Both of the cells seen in $B$ contain vimentin-like filaments, one of them (arrow) being an enteric glial cell as shown by the Ran-1 surface staining (cf. GFAP and glutamine synthetase). 
mentin-like immunoreactivity and to demonstrate its continued expression independent of contact with neuronal soma, we immunostained cultures similar to those used for GFAP localization. Immunoreactivity was absent from neurons but present in all of the enteric glia, which show considerable morphological variation in culture (Jessen et al., 1983a), and in connective tissue cells (Fig. 5).

Glutamine synthetase-like immunoreactivity. In frozen sections glutamine synthetase-like immunoreactivity was found inside myenteric ganglia and submucous ganglia in a location similar to that of GFAP and vimentinlike immunoreactivity, but in a nonfilamentous pattern (Fig. 6). The staining was comparable in intensity and pattern to that seen in astrocytes in frozen sections of cerebellum.

Immunostaining of culture preparations of the myenteric plexus, similar to those used previously, confirmed that the glutamine synthetase-like immunoreactivity was clearly present in and restricted to enteric glia, and the staining pattern was similar to that seen in cultured astrocytes (Fig. 7).

\section{Cell surface properties}

To overcome well recognized technical difficulties in the visualization of surface molecules in tissue sections, we used the myenteric plexus freshly dissected from the gut to study the surface properties of the enteric glial cells. Using such preparations, any risk of changes in surface features resulting from cell culturing is avoided, while the semi-monolayer arrangement of neurons and glia in the myenteric ganglia allows easy visualization of surface antigens by immunohistochemical methods (Jessen and Burnstock, 1982).

We investigated the distribution of the glial membrane molecules Ran-1, Ran-2, and galactocerebroside. To examine the regulation of these molecules, we also studied their expression in enteric glia which had been maintained in culture for 7 to 10 days. In addition we used whole mount preparations and cultures to study the cellular distribution of the extracellular matrix protein fibronectin.

$R A N-1$. We were unable to detect Ran-1 on enteric glial cells in situ in experiments on freshly dissected myenteric plexus from rats ranging in age from 4 days to 4 weeks. Because enzymes were used to remove the plexus from the gut wall, in some experiments we treated DRG in a comparable manner. Ran-1 was still clearly detectable, although at a reduced level, in the satellite and Schwann cells of the DRG indicating that the failure to detect Ran-1 in enteric glial cells was not due to the enzyme treatment or due to a failure of the Ran-1 antibody to penetrate into the plexus, since antibodies penetrated the DRG which has considerably more extensive connective tissue sheaths than the loose connective tissue in which the plexus is embedded in situ.

In sharp contrast, enteric glia maintained in culture for 7 to 10 days expressed high levels of Ran-1, showing a staining intensity similar to that found in cultured Schwann or satellite cells (Figs. 7 and 8). The antigen was not expressed by neurons or fibroblasts in the cultures. We were able to confirm that Ran-1 molecules were localized on the surface of cultured enteric glial cells which also contained intracellular GFAP, vimentin, or glutamine synthetase immunoreactivity by the use of double fluorochrome immunofluorescence (Figs. 5 and 7). All or nearly all of the Ran- $1^{+}$cells had GFAP and vimentin-like staining and glutamine synthetase activity. Fibroblasts and all neurons examined (although detailed counts were not made) were negative for Ran-1, GFAP,

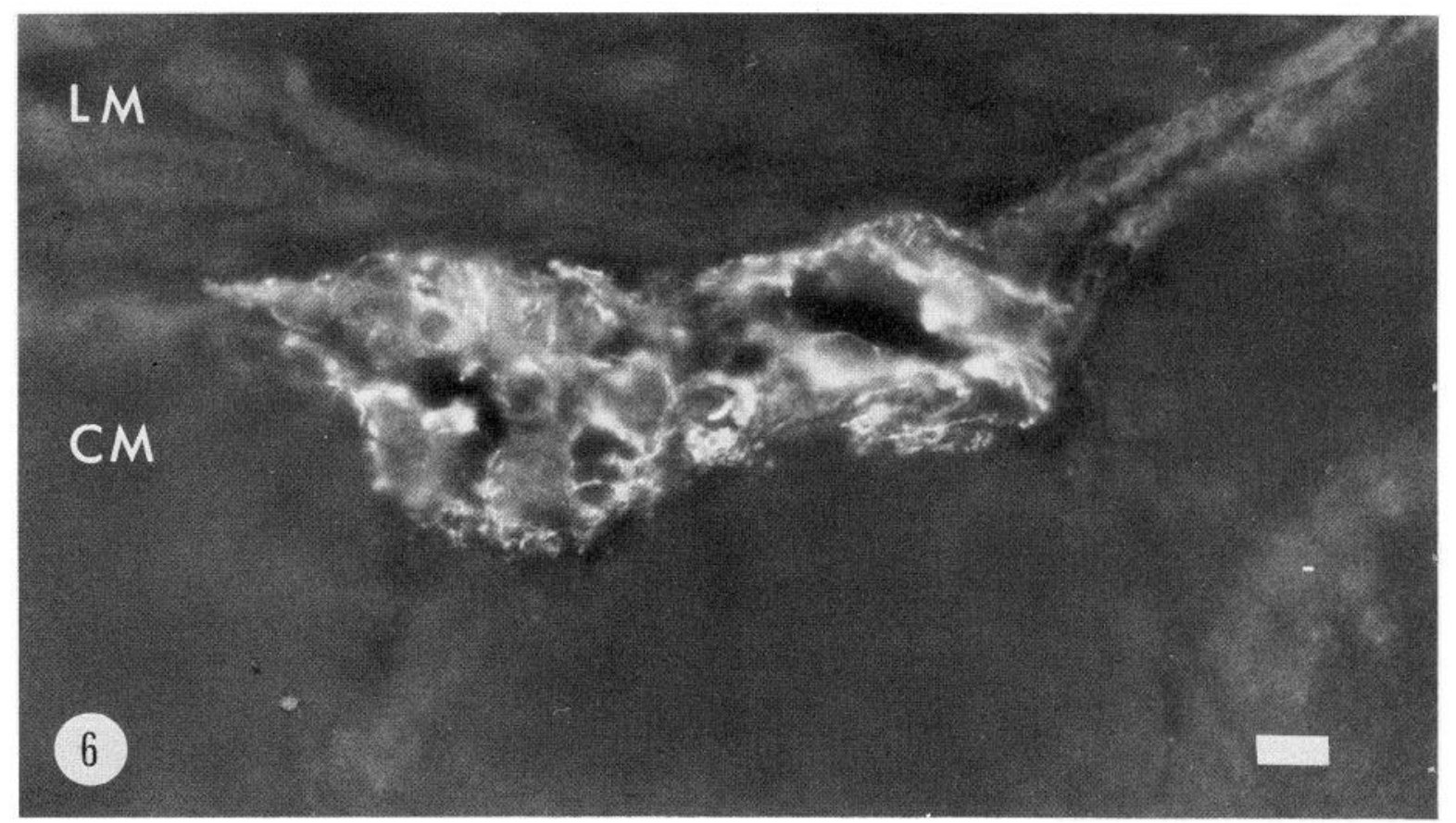

Figure 6. Glutamine synthetase-like immunoreactivity in an explant culture of a myenteric plexus ganglion in the proximal colon. Immunostaining in the proximal colon is confined to the glial cells in the ganglion. $L M$, longitudinal muscle; $C M$, circular muscle. Bar, $10 \mu \mathrm{m}$. 

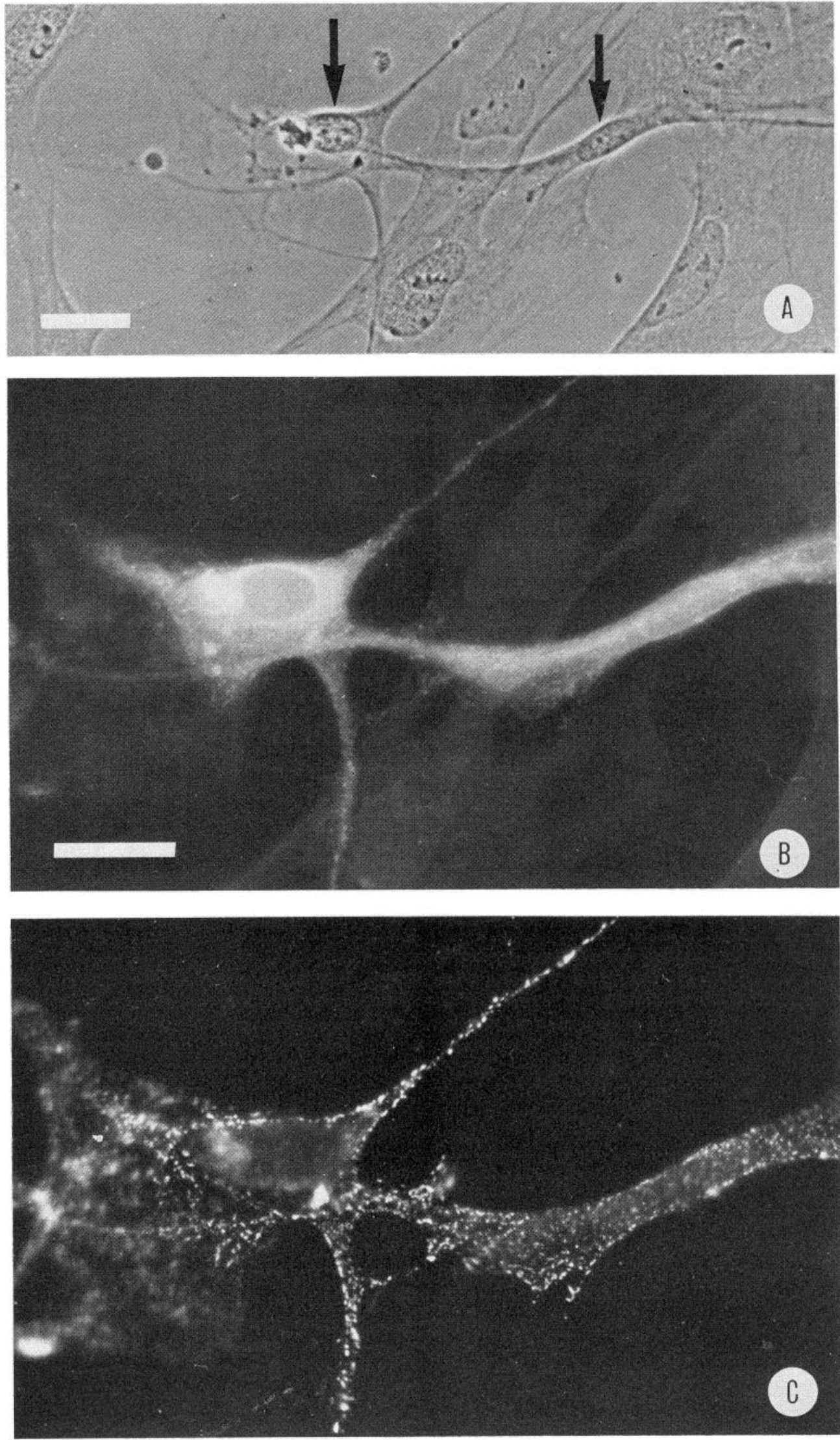

Figure 7. Glutamine synthetase-like and Ran-1 immunoreactivity in an explant culture of the myenteric plexus from 8-dayold rat proximal colon maintained in vitro for 10 days. $A$, Phase contrast optics reveal the presence of several cells in the field. $B a r, 10 \mu \mathrm{m}$. $B$, Fluorescein optics visualize glutamine synthetase-like immunoreactivity, restricted to two of the cells seen in $A$ (arrows). Bar, $10 \mu \mathrm{m}$. $C$, Rhodamine optics show that the same two cells are labeled; magnification as in $B$. Note that $A$ is a lower magnification than $B$ and $C$. 

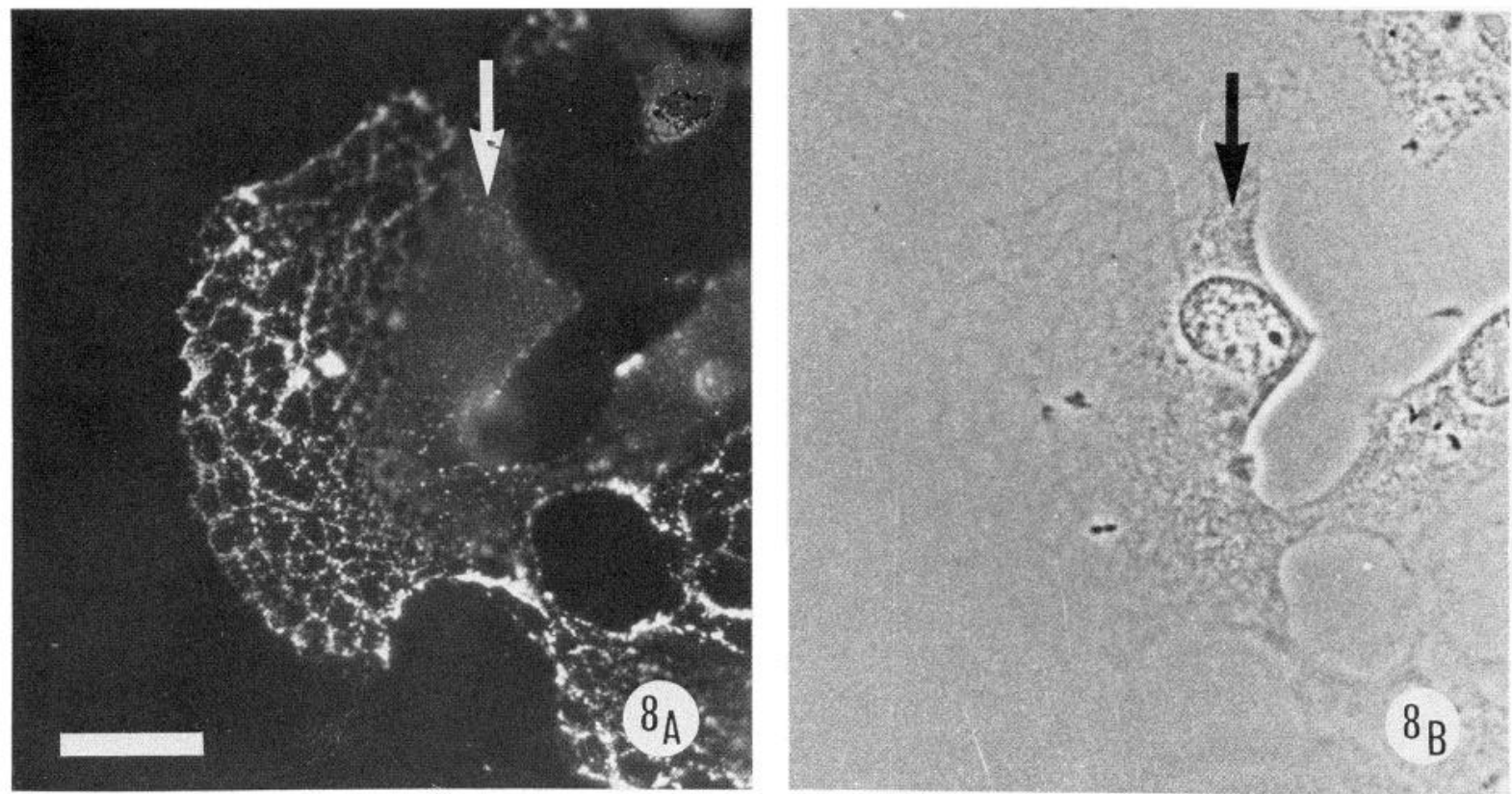

Figure 8. Ran-1 immunoreactivity in cultured enteric glia. The cells are viewed with $(A)$ rhodamine and $(B)$ phase contrast optics. The arrowed cell exhibits a flattened morphology characteristic of enteric glia and shows Ran-1 surface labeling. Bar, 10 $\mu \mathrm{m}$.

and glutamine synthetase, whereas both fibroblasts and enteric glial cells contained vimentin.

$R A N-2$. This antigen was undetectable on the surface of enteric glia in freshly dissected myenteric plexus from 7-day-old rats but was clearly detectable in 14-day-old rats, only reaching full intensity in plexuses isolated from 4-week-old rats (Fig. 9). Examination of the dissected plexus in different planes of focus of the microscope revealed that the antigen was present on the surface of most, if not all, glial cells within the ganglia, the brightly speckled structures interweaving among and surrounding the neurons that, as far as we could judge, were always unstained. This characteristic staining pattern, due to the three-dimensional nature of the preparation, is quite inconsistent with the possibility that the antigen resides in any connective tissue remnants that may surround the ganglia after the dissection. In explant cultures from 3 -week-old rats, the oldest age at which we were able to culture the myenteric plexus, the antigen was not present on the surface of cultured glial cells after 10 days in culture (Fig. 10), even though it was clearly present in situ at this stage.

Galactocerebroside. The myelin-associated glycolipid galactocerebroside was not expressed by enteric glial cells either in freshly isolated myenteric plexus or in tissue culture.

Fibronectin. In whole mount preparations of the myenteric plexus, fibronectin-like immunoreactivity was associated with cells in the connective tissue layer that separates the longitudinal and circular muscle layers of the muscle coat of the gut wall, in which the myenteric plexus is embedded. Immunoreactivity was absent from the ganglia and interconnecting strands of the plexus.

In culture, large quantities of fibronectin-immunoreactive fibrous material was associated with the fibroblasts, whereas very little immunoreactivity was found on enteric glial cells or neurons (Fig. 11).

\section{Discussion}

A detailed comparison of the antigenic properties of enteric glia with those seen in other glial cells is presented in Table I. Two main conclusions emerge.

First, similarities between enteric glia and astrocytes are present not only at a morphological but also at a molecular level. Thus, in situ most astrocytes and enteric glia express the Ran-2 antigen, GFAP, and glutamine synthetase. Ran-1, found on most Schwann and satellite cells, is absent from both enteric glia and astrocytes in $s i t u$, although it appears in enteric glia in culture (see below). Moreover, enteric glia, like astrocytes (Dahl, 1981), have low levels of GFAP and high levels of vimentin when immature, whereas in mature cells the reverse is true. Their astrocyte-like ultrastructure and relationship with neurons is well documented. The enteric glia are irregular in shape and carry long, branching processes, which, with neurites, form an extensive neuropil; they contain bundles of $10-\mathrm{nm}$ glio-filaments and many glycogen granules and are not individually covered by a basal lamina (Gabella, 1971, 1981; Cook and Burnstock, 1976; Wilson et al., 1981; Komuro et al., 1982).

Taken together, the molecular and morphological evidence supports the idea that enteric glia and astrocytes may share common functions not carried out by Schwann and satellite cells. This point now awaits further study.

Second, the present results strengthen previous suggestions, based on ultrastructure (Gabella, 1981) and tissue culture studies (Jessen et al., 1983a), that enteric glia differ significantly from Schwann and satellite cells. Moreover, these cells constitute a major population of peripheral glia, since the ENS is, in terms of neuronal 

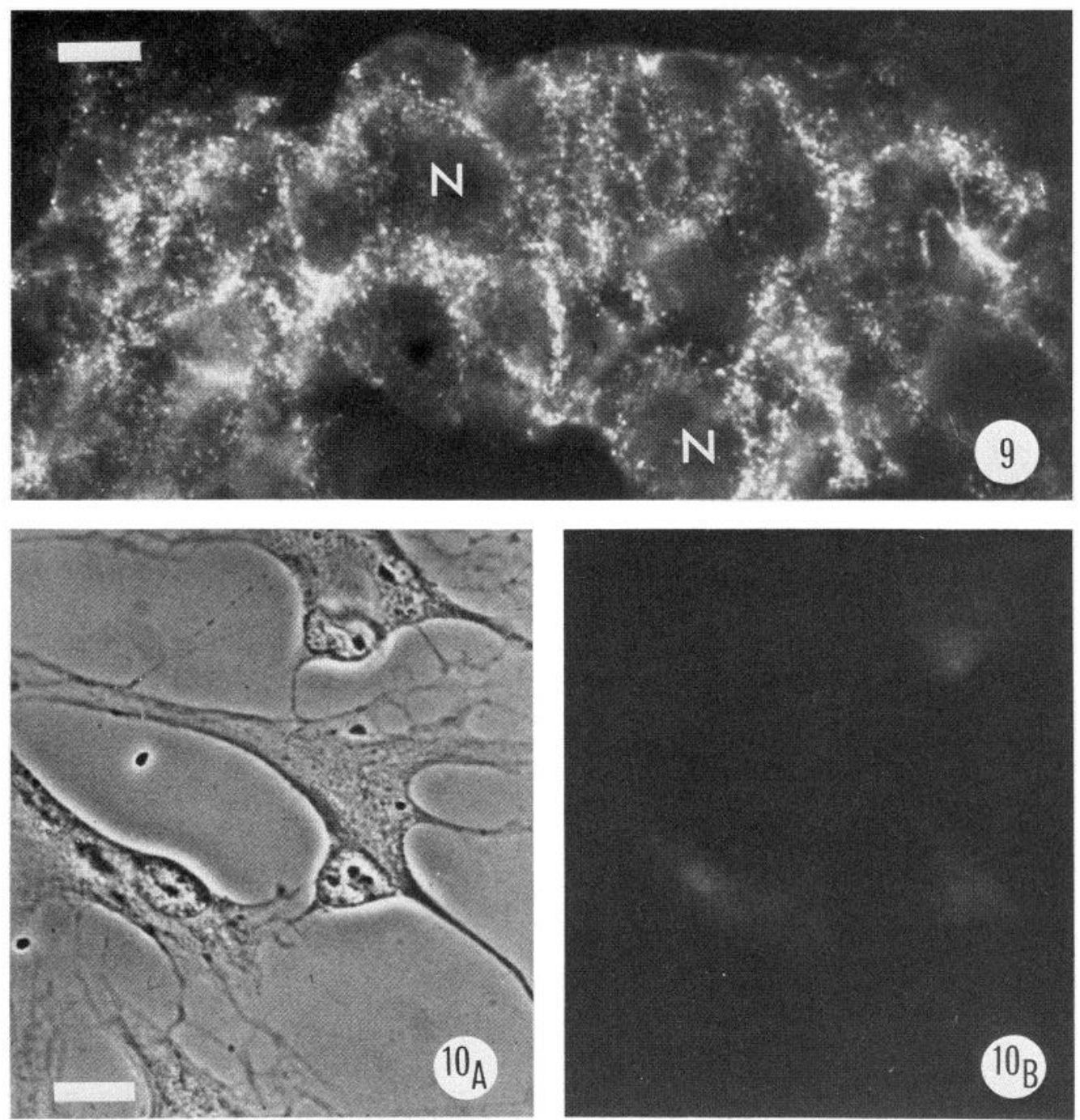

Figure 9. Ran-2 immunoreactivity in a myenteric ganglion freshly isolated from the gut wall of 4-week-old proximal colon. Intense labeling is evident on the cell surface of the enteric glia surrounding unlabeled neurons (examples labeled with $N$ ). Bar, $10 \mu \mathrm{m}$.

Figure 10. Culture of enteric glial cells from 3-week-old proximal colon treated with antibodies to Ran-2. The cells are viewed with $(A)$ phase contrast and $(B)$ rhodamine optics. No Ran-2 antigen can be detected on these cells; contrast with Figure 9 . Bar, $10 \mu \mathrm{m}$.

numbers, the largest major division of the PNS, and the glial cells outnumber enteric neurons by about 2 to 1 . It therefore seems logical to regard these cells as a third and separate category of peripheral glia, in addition to Schwann cells and satellite cells.

A dependency on exogenous factors, such as direct cell-cell or hormonal signalling, for the expression of the in situ phenotype is sometimes revealed when cells are placed in the simplified environment of culture. Of the molecules studied here, only the expression of the surface antigens Ran-1 and Ran-2 showed well defined changes in response to culture: Ran-1, not detectable postnatally in situ, appeared in high levels in culture, while Ran-2, which is clearly present in situ from about the 2nd postnatal week onward, disappeared. It is unlikely that the failure to detect Ran-1 on enteric glia in situ is due to a failure of the antibody to penetrate into the plexus since comparable experiments involving neuronal anti- gens (unpublished observations) indicate that they can easily be visualized on the neuronal cell bodies and processes within the plexus. Thus, with respect to these two antigens, the phenotype of enteric glia changes in culture so that it resembles cultured Schwann and satellite cells (Table I). Although the significance of this similarity is not clear, it may be instructive to relate these changes to the developmental expression of these molecules. In early embryos, Ran-1 is not confined to nervous tissue (Fields et al., 1975), only later achieving a more restricted cellular distribution and becoming, among glia, restricted to Schwann and satellite cells. In contrast, Ran-2 develops late on enteric glia, being undetectable at 1 week after birth and only reaching adult levels at 4 weeks. Thus, for Ran-2 and possibly for Ran1 , the culture phenotype of these cells is similar to that found before their final developmental differentiation, and the surface changes seen in culture may represent a 

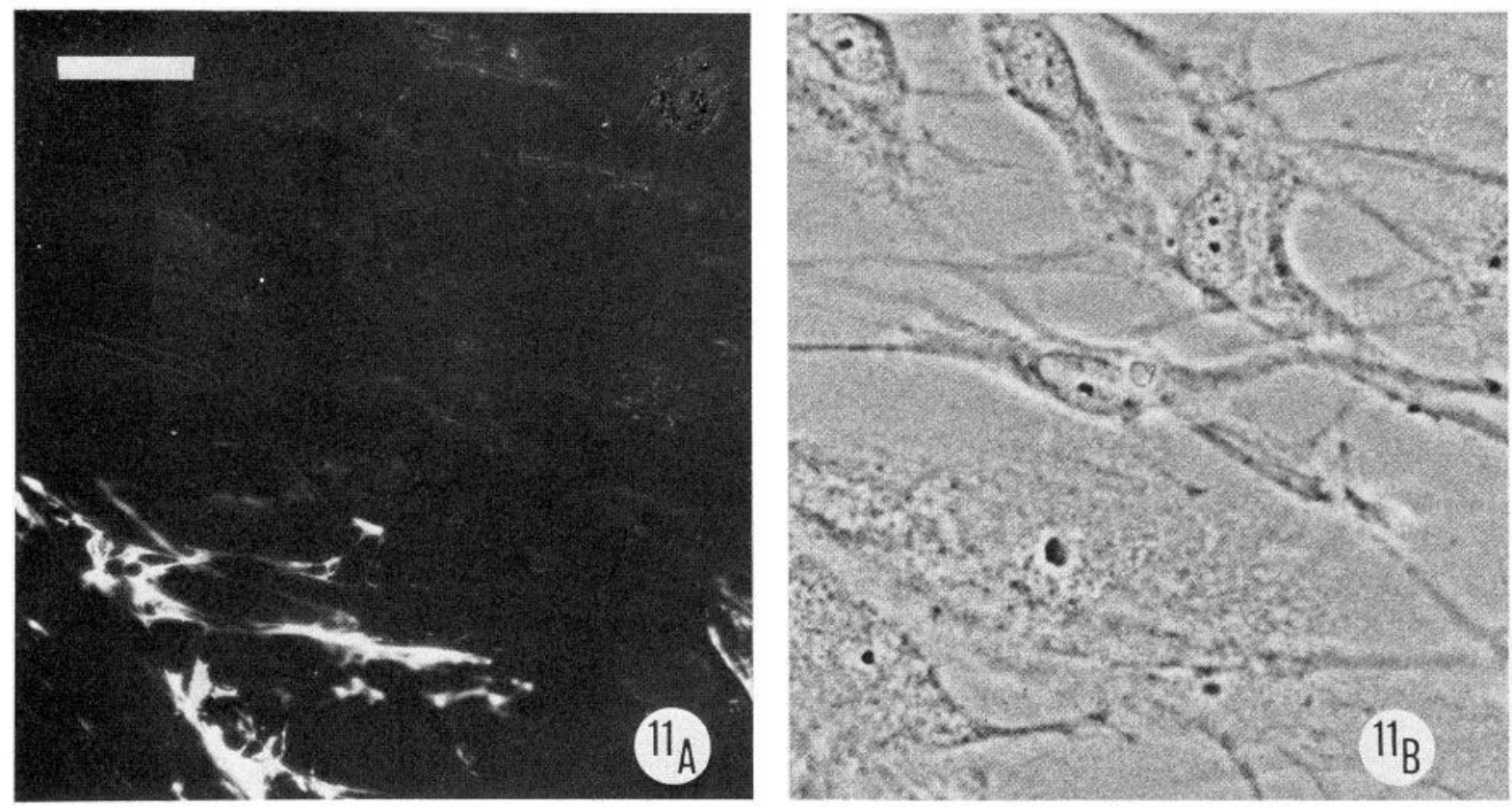

Figure 11. Fibronectin-like immunoreactivity in a culture of the myenteric plexus. $A$, Rhodamine and $B$, phase contrast optics. Note that the flat, fibroblastic cells occupying the lower left-hand part of the field in $B$ are associated with feathery immunoreactivity, while the enteric glial cells in the upper part of the field are virtually unstained. Explant culture from 9-day-old rat proximal colon maintained in vitro for 9 days. Bar, $10 \mu \mathrm{m}$.

TABLE I

Comparison of antigenic properties of glial cells

\begin{tabular}{|c|c|c|c|c|c|c|}
\hline & \multicolumn{2}{|c|}{ Enteric Glia } & \multicolumn{2}{|c|}{ Astrocytes } & \multicolumn{2}{|c|}{$\begin{array}{l}\text { Schwann and } \\
\text { Satellite Cells }\end{array}$} \\
\hline & $\begin{array}{l}\text { In } \\
\text { situ }\end{array}$ & $\begin{array}{c}\text { In } \\
\text { culture }\end{array}$ & $\begin{array}{c}\text { In } \\
\text { situ }\end{array}$ & $\begin{array}{c}\text { In } \\
\text { culture }\end{array}$ & $\begin{array}{c}\text { In } \\
\text { situ }\end{array}$ & $\begin{array}{c}\text { In } \\
\text { culture }\end{array}$ \\
\hline GFAP $^{a}$ & + & + & + & + & \pm & \\
\hline Glutamine synthetase $^{b}$ & + & + & + & + & \pm & \\
\hline Ran- $2^{c}$ & + & - & + & + & \pm & \\
\hline Ran- $1^{d}$ & - & + & - & - & + & + \\
\hline Vimentin $^{e}$ & + & + & + & + & + & + \\
\hline Galactocerebroside $^{f}$ & - & - & - & - & \pm & - \\
\hline Fibronectin $^{g}$ & - & - & - & - & - & - \\
\hline
\end{tabular}

${ }^{a}$ GFAP is expressed by astrocytes in situ (Schachner et al., 1977) and in culture (Bock et al., 1977). In situ GFAP is also expressed by a minority of Schwann cells in sciatic nerve (Yen and Fields, 1981) and other nerves and by a minority of satellite cells in DRG (R. Mirsky, and K. R. Jessen, manuscript in preparation).

${ }^{b}$ Glutamine synthetase is found in astrocytes in situ (MartinezHernandez et al., 1977) and in culture, and in a minority of Schwann cells in teased sciatic nerve preparations (R. Mirsky and K. R. Jessen, manuscript in preparation).

${ }^{c}$ Ran-2 is present in astrocytes, ependymal cells, and leptomeningeal cells in culture (Bartlett et al., 1981) and on astrocytes in situ. It is present on a minority of Schwann cells in teased sciatic nerve preparations but absent from Schwann cells after several days in culture ( $R$. Mirsky and K. R. Jessen, manuscript in preparation).

${ }^{d}$ Ran-1 is absent from astrocytes in culture (Raff et al., 1979) and in teased optic nerve preparations ( $R$. Mirsky and K. R. Jessen, manuscript in preparation). It is present on both Schwann and satellite cells in culture (Fields et al., 1978; Brockes et al., 1979). As shown here, it is present at low levels on Schwann cells in teased sciatic nerve preparations and at low levels on both Schwann and satellite cells in enzyme-treated DRG preparations.

'Vimentin is expressed by astrocytes in situ and in culture, by Schwann cells in situ and in culture (Yen and Fields, 1981), and by developmental reversal. Phenomena of this kind are observed quite frequently, e.g., with respect to membrane specializations and cytoskeletal proteins in smooth muscle (Chamley et al., 1974; Gröschel-Stewart et al., 1975), myelin-related molecules in Schwann cells (Mirsky et al., 1980), and vimentin in several cell types (Dahl et al., 1981).

In conclusion, a general consideration of the results discussed above indicates that at the molecular level enteric glia are closely related to other glia, sharing with them antigens highly restricted to glial cells including Ran-1, Ran-2, GFAP, glutamine synthetase, and, as reported by others, S-100 (Ludwin et al., 1976; Ferri et al., 1982). Furthermore, like other glia they are fibronectin negative. The adult phenotype of enteric glia in situ closely resembles that of astrocytes, while in culture some of their cell surface features change, reverting to those seen during development. Therefore the enteric glia may be more dependent than astrocytes on ongoing cell-cell signalling for the maintenance of full differentiation. Because these cells possess distinctive molecular features and numerically form one of the major populations of peripheral glia, it is appropriate to classify them as a

satellite cells in situ and in culture (R. Mirsky and K. R. Jessen, manuscript in preparation) and by many other cell types.

${ }^{f}$ Galactocerebroside is expressed by myelin-producing Schwann cells but is not present in other Schwann and satellite cells. It disappears from myelin-producing Schwann cells in culture (Mirsky et al., 1980) and is not present in astrocytes (Raff et al., 1979).

${ }^{g}$ Fibronectin is not expressed by astrocytes in situ (Schachner et al., 1978) or in culture (Raff et al., 1979) or by Schwann cells in situ or in culture (Raff et al., 1979; Yen and Fields, 1981). 
third distinctive category of peripheral glial cells, in addition to satellite and Schwann cells. The molecular similarities between these cells and astrocytes, in addition to their anatomical resemblance, suggest that a further study of enteric glia will provide new insights into the role of glia in integrative nervous tissues.

\section{References}

Baluk, P., K. R. Jessen, M. J. Saffrey, and G. Burnstock (1983) The enteric nervous system in tissue culture. II. Ultrastructural studies on cell types and their relationships. Brain Res. 262: $36-48$.

Bartlett, P. F., M. D. Noble, R. M. Pruss, M. C. Raff, S. Rattray, and C. A. Williams (1981) Rat neural antigen-2 (Ran-2): A cell surface antigen on astrocytes, ependymal cells, Müller cells and leptomeninges defined by a monoclonal antibody. Brain Res. 204: 339-352.

Bock, E., M. Moller, C. Nissen, and M. Sensenbrenner (1977) Glial fibrillary acidic protein in primary astroglial cultures derived from newborn rat brain. FEBS Lett. 83: 207-211.

Brockes, J. P., K. L. Fields, and M. C. Raff (1977) A surface antigenic marker for rat Schwann cells. Nature 266: 364366.

Brockes, J. P., K. L. Fields, and M. C. Raff (1979) Studies on cultured rat Schwann cells. I. Establishment of purified populations from cultures of peripheral nerve. Brain Res. 165: $105-118$.

Chamley, J. H., G. R. Campbell, and G. Burnstock (1974) Dedifferentiation, redifferentiation and bundle formation of smooth muscle cells in tissue culture: The influence of cell number and nerve fibers. J. Embryol. Exp. Morphol. 32: 297323.

Cook, R. D., and G. Burnstock (1976) The ultrastructure of Auerbach's plexus in the guinea-pig. II. Non-neuronal elements. J. Neurocytol. 5: 195-206.

Costa, M., R. Buffa, J. B. Furness, and E. Solcia (1980) Immunohistochemical localisation of polypeptides in peripheral autonomic nerves using whole mount preparations. Histo chemistry $65: 157-165$.

Dahl, D. (1981) The vimentin-GFA protein transition in rat neuroglia cytoskeleton occurs at the time of myelination. J. Neurosci. Res. 6: 741-748.

Dahl, D., D. C. Rueger, A. Bignami, K. Weber, and M. Osborn (1981) Vimentin, the 57000 molecular weight protein of fibroblast filaments, is the major cytoskeletal component in immature glia. Eur. J. Cell Biol. 24: 191-196.

Ferri, G.-L., L. Probert, D. Cocchia, F. Michetti, P. J. Marangos, and J. M. Polak (1982) Evidence for the presence of S100 protein in the glial component of the human enteric nervous system. Nature (Lond.) 297: 409-412.

Fields, K. L., C. Gosling, M. Megson, and P. L. Stern (1975) New cell surface antigens in rat defined by tumors of the nervous system. Proc. Natl. Acad. Sci. U. S. A. 72: 12861300 .

Fields, K. L., J. P. Brockes, R. Mirsky, and L. M. B. Wendon (1978) Cell surface markers for distinguishing different types of rat dorsal root ganglion cells in culture. Cell 14: 43-51.

Frank, F. D., and I. Warren (1981) Aortic smonth muscle cells contain vimentin instead of desmin. Proc. Natl. Acad. Sci. U. S. A. 78: 3020-3027.

Furness, J. B., and Costa, M. (1980) Types of nerves in the enteric nervous system. Neuroscience 5: 1-20.

Gabella, G. (1971) Glial cells in the myenteric plexus. Z. Naturforsch. 266: 244-245.

Gabella, G. (1981) Structure of the nerve plexuses of the mammalian intestine: The enteric glial cells. Neuroscience
6: $125-136$.

Gershon, M. D. (1981) The enteric nervous system. Annu. Rev. Neurosci. 4: 227-272.

Gröschel-Stewart, U., J. M. Chamley, G. R. Campbell, and G. Burnstock (1975) Changes in myosin distribution in dedifferentiating and redifferentiating smooth muscle cells in tissue culture. Cell Tissue Res. 165: 13-22.

Jessen, K. R., and G. Burnstock (1982) The enteric nervous system in tissue culture: A new mammalian model for the study of complex nervous networks. Trends Auton. Pharmacol. 2: 95-115.

Jessen, K. R., and R. Mirsky (1980) Glial cells in the enteric nervous system contain glial fibrillary acidic protein. Nature 286: 736-737.

Jessen, K. R., M. J. Saffrey, and G. Burnstock (1983a). The enteric nervous system in tissue culture. I. Cell types and their interactions in explants of the myenteric and submucous plexuses from guinea-pig, rabbit and rat. Brain Res. 262: 17-35.

Jessen, K. R., M. J. Saffrey, P. Baluk, and G. Burnstock (1983b) The enteric nervous system in tissue culture. III. Studies on neuronal survival and the retention of biochemical and morphological differentiation. Brain Res. 262: 49-62.

Komuro, T., P. Baluk, and G. Burnstock (1982) An ultrastructural study of neurons and non-neuronal cells in the myenteric plexus of the rabbit colon. Neuroscience 7: 1797-1806.

Lazarides, E. (1980) Intermediate filaments as mechanical in tegrators of cellular space. Nature 283: 249-256.

Ludwin, S. K., J. C. Kosek, and L. F. Eng (1976) The topographical distribution of $\mathrm{S}-100$ and GFA proteins in the adult rat brain: An immunohistochemical study using horseradish peroxidase-labelled antibodies. J. Comp. Neurol. 165: 197208.

Martinez-Hernandez, A., K. P. Bell, and M. D. Norenberg (1977) Glutamine synthetase: Glial localisation in brain. Science 195: 1356-1358.

Mirsky, R., J. Winter, E. R. Abney, R. M. Pruss, J. Gavrilovic, and M. C. Raff (1980) Myelin-specific proteins and glycolipids in rat Schwann cells and oligodendrocytes in culture. J. Cell Biol. 84: 483-494.

Raff, M. C., R. Mirsky, K. L. Fields, R. P. Lisak, S. H. Dorfman, D. H. Silberberg, N. A. Gregson, S. Liebowitz, and M. C. Kennedy (1978) Galactocerebroside is a specific cell-surface antigenic marker for oligodendrocytes in culture. Nature 271: 813-816.

Raff, M. C., K. L. Fields, S.-I. Hakomori, R. Mirsky, R. M. Pruss, and J. Winter (1979) Cell-type-specific markers for distinguishing and studying neurons and the major classes of glial cells in culture. Brain Res. 174: 283-308.

Ranscht, B., P. A. Clapshaw, J. Price, M. Noble, and W. Seifert (1982) Development of oligodendrocytes and Schwann cells studied with a monoclonal antibody against galactocerebroside. Proc. Natl. Acad. Sci. U. S. A. 79: 2709-2713.

Ramaekers, F. C. S., J. J. G. Puts, A. Kant, O. Moesker, P. H. K. Jap, and G. P. Vooijs (1982) Use of antibodies to intermediate filaments in the characterization of human tumours. Cold Spring Harbor Symp. Quant. Biol. 66: 331-339.

Schachner, M., E. T. Hedley-Whyte, D. W. Hsu, G. Schoonmaker, and A. Bignami (1977) Ultrastructural localisation of glial fibrillary acidic protein in mouse cerebellum by immunoperoxidase labelling. J. Cell Biol. 75: 67-73.

Schachner, M., G. Schoonmaker, and R. O. Hynes (1978) Cellular and subcellular localisation of LETS protein in the nervous sytem. Brain Res. 158: 149-158.

Stefani, M., C. De Martino, and L. Zamboni (1967) Fixation of ejaculated spermatozoa for electron microscopy. Nature (London) 216: 173-174. 
Wartiovaara, J., E. Linder, E. Ruoslahti, and A. Vaheri (1974) Wood, J. D. (1981) Physiology of the enteric nervous system. Distribution of fibroblast surface antigen. J. Exp. Med. 140: 1522-1533.

In Physiology of the Gastrointestinal Tract, L. R. Johnson, ed., pp. 1-37, Raven Press, New York.

Wilson, A. J., J. B. Furness, and M. Costa (1981) The fine structure of the submucous plexus of the guinea-pig ileum. I. The ganglia, neurons, Schwann cells and neuropil. J. Neurocytol. 10: 759-784.

Yen, S. -H., and K. L. Fields (1981) Antibodies to neurofilament, glial filament and fibroblast intermediate filament proteins bind to different cell types of the nervous system. $J$. Cell Biol. 88: 115-126. 